\title{
Contour specificity of the McCollough effect
}

\author{
LINDSAY T. SHARPE and RICHARD C. TEES \\ University of British Columbia, 2075 Wesbrook Place, Vancouver, B.C., Canada
}

\begin{abstract}
Subjective estimates of McCollough aftereffect strength are significantly reduced when certain spatial features of the line grating patterns are manipulated. Results are dependent upon whether the spatial parameters of the test or inspection patterns are altered. Changing the angular slant, contour sharpness, or contour completeness of the inspection gratings does not affect aftereffect strength, but changing the spatial frequency, contour sharpness, or contour completeness of the test gratings does. The implications of these results are discussed with regard to theories offered to explain the McCollough effect.
\end{abstract}

The McCollough effect, a long-lasting color aftereffect, can be elicited by exposing subjects to chromatic line-grating patterns (McCollough, 1965). Such an aftereffect is contingent upon the retinal orientation of achromatic versions of the inspection pattern and is roughly complementary to the adapting color (cf. Stromeyer, 1969). Extensive descriptions of this phenomenon have been provided (e.g., Fidell, 1970; Harris \& Gibson, 1968; McKay \& McKay, 1973; Murch, 1972; Stromeyer, 1969; White \& Ellis, Note 1; White \& Riggs, Note 2) and a number of analogous contingent aftereffects have been discovered. The ever-increasing list includes: a motion-contingent color aftereffect (Hepler, 1968; Stromeyer \& Mansfield, 1970), a color-contingent motion aftereffect (Favreau, Emerson, \& Corballis, 1972), a spatial frequencycontingent color aftereffect (Breitmeyer \& Cooper, 1972; Leppmann, 1973; Lovegrove \& Over, 1972; Teft \& Clark, 1968; May \& Matteson, Note 3), a motion-contingent texture aftereffect (Walker, 1972), and an angle- and curvature-contingent color aftereffect (Riggs, 1973; White \& Riggs, 1974).

Theoretical accounts of these afterphenomena usually implicate the adaptation of particular kinds of sensory neurons (cf. Harris \& Gibson, 1968; Lovegrove, Over, \& Broerse, 1972; McCollough, 1965; Murch, 1972), often suggesting that associative learning (cf. Jones \& Holding, 1975; Leppman, 1973) or cortical lability (cf. Creutzfeldt \& Heggelund, 1975) facilitates the inhibitory linkages between excited units. But no single account satisfactorily explains all the characteristics of contingent aftereffects. Since many of the relevant characteristics have not been fully examined, perhaps, for the pres-

This investigation was conducted while the first author was receiving a National Research Council of Canada postgraduate scholarship. It was supported by a National Research Council of Canada grant (AP0179) to the second author. Requests for reprints should be sent to L. T. Sharpe, who is now at the Center for Visual Science, Department of Psychology, University of Rochester, Rochester, New York 14627. ent, oversimplified neurophysiological model building is best avoided (cf. recent review article by Skowbo, Timney, Gentry, \& Morant, 1975). Instead, the effects should be looked at more systematically to obtain as good an experimental description of their properties as possible.

\section{EXPERIMENT 1}

Investigations of the McCollough effect usually employ patterns composed of horizontally and vertically oriented line grids as inspection stimuli. Fidell (1970), in his examination of the orientation specificity of the McCollough effect, however, reported that color aftereffects can be produced to all orientations of inspection stimuli as long as they are at right angles to one another. In particular, he elicited strong aftereffects from four pairs of inspection gratings differing in their angular orientation but not in their angular separation: $90^{\circ}$ vs. $0^{\circ}, 135^{\circ}$ vs. $45^{\circ}, 158^{\circ}$ vs. $68^{\circ}$, and $169^{\circ}$ vs. $79^{\circ}$. Unfortunately, he did not compare the relative magnitude of these aftereffects. Such observations might provide insight into the feasibility of the various models offered to account for the McCollough effect. Accordingly, the purpose of this experiment is to explore the influence of inspection grating orientation on perceived aftereffect magnitude.

\footnotetext{
Method

Subjects. The subjects were 10 male and 10 female University of British Columbia students and staff. Twelve subjects were not familiar with the McCollough effect; the remaining eight were (although they were naive with respect to the experimental hypothesis). The mean age of subjects was approximately 25 years.

Apparatus and Grating Stimuli. All of the inspection and test stimuli used were projected transparencies (35-mm slides) of $2: 1$ white/black gratings. They were photographic reproductions of Lettraset patterns and were available in four different angular orientations: $0^{\circ}, 45^{\circ}, 90^{\circ}$, and $135^{\circ}$. When seen by the subject, the black and white bars of the inspection gratings subtended approximately $0.04^{\circ}$ and $0.08^{\circ}$ of visual angle. This corresponded to a spatial frequency of $8.3 \mathrm{c} / \mathrm{deg}$ (spatial frequency = reciprocal of the angular width of one white + one black bar). Test gratings
} 
differed from inspection gratings insofar as one-half of each pattern was a line grating of one orientation (e.g., $45^{\circ}$ or $0^{\circ}$ ) and the other half was a line grating of the same spatial frequency but the orthogonal orientation (e.g., $135^{\circ}$ or $90^{\circ}$ ). They were available in six different spatial frequencies: $2.0,2.5,3.4,4.3$, 8.3 , and $12.6 \mathrm{c} / \mathrm{deg}$. Both the inspection and test grating slides were front projected onto a $.5-\mathrm{sq}-\mathrm{m}$ white screen via slide projectors with $300-\mathrm{W}$ projection bulbs. The projectors were placed on a table $1.5 \mathrm{~m}$ from the screen and $.6 \mathrm{~m}$ to the right of the subject. When colored gratings were required, they were produced by projecting the transparencies through either a Baltzers red (dominant wavelength $=521 \mathrm{~nm}$ ) or green (dominant wavelength $=624 \mathrm{~nm}$ ) interference filter. These filters have a half-peak bandwidth of approximately $10 \mathrm{~nm}$. The luminance of the colored grating bars was approximately $4.3 \mathrm{~cd} / \mathrm{m}^{2}$. The white grating bars were projected at a comparable level by superimposing Baltzers neutral density filters in front of the black/white transparencies.

Procedure. The subjects were randomly assigned to two conditions. In Condition 1 , the subjects $(N=10)$ were individually shown all the test stimuli and asked if they observed any color differences between the two halves. Each subject then viewed a sequence of orthognnally oriented and oppositely colored line gratings (either red $135^{\circ}$ and green $45^{\circ}$ or red $0^{\circ}$ and green $90^{\circ}$ ) with one eye for $10 \mathrm{~min}$ while wearing an eyepatch over the other eye. During this adaptation, the subject was instructed to fixate in the same central region as the gratings were interchanged every $10 \mathrm{sec}$. After $10 \mathrm{~min}$, the subject was tested with the achromatic patterns for the :resence of $\mathrm{McC}$ Collough effects in both the exposed and covered eye. Next, the subject viewed the remaining pair of orthogonal line gratings with his previously covered eye while wearing the eyepatch over his previously exposed eye. After $10 \mathrm{~min}$, the subject was again tested for the presence of McCollough effects in both eyes. During the testing sequences, the subjects responded by giving verbal judgments of their visual observations. They were initially shown the combination test pattern composed of the same spatial frequencies and orientations as the inspection gratings, and were asked if they saw any color differences between the opposite halves when viewing with the adapted eye; if so, to assign simple color names to the different halves; then to assign a value of 5 on a scale from 0 to 5 to the strongest aftereffect(s) elicited; and finally to scale all subsequently presented test patterns for strength of aftereffect. This entire procedure was repeated for the originally covered eye as a control to check for interocular transfer. After completion of both inspection and testing sequences, the subject was required to cross-compare the relative magnitude of the aftereffects produced in his two eyes. Each subject was instructed to alternately open and close his eyes and to sequentially view the $0^{\circ} / 90^{\circ}$ and $45^{\circ} / 135^{\circ}$ combination test patterns. The subject assigned a value of 5 to the strongest elicited aftereffect (regardless of eye) and the appropriate values to the other (weaker) aftereffects. One value was assigned to each grating orientation $0^{\circ}, 45^{\circ}, 90^{\circ}$, and $135^{\circ}$

In Condition $2(N=10)$, the same pairs of orientationcontingent color aftereffects were induced; however, the adaptation sequences were simultaneous rather than successive. Thus, subjects were presented with only one 10 -min adaptation period during which they individually viewed an alternating sequence of red $135^{\circ}$ oblique, green $45^{\circ}$ oblique, red $0^{\circ}$ horizontal, and green $90^{\circ}$ line gratings. This procedure was introduced to eliminate three possible confounding factors in the original design. First, the temporal delay between the two inspection conditions might have affected the decay rate of the color aftereffects (MacKay \& MacKay, 1974; Riggs, White, \& Eimas, 1974). Second, binocular interactions of the McCollough effect may have influenced monocular magnitude estimates (Mikaelian, 1975). Third, adapting each subject's eyes to different pairs of stimuli (i.e., either red $135^{\circ}$ and green $45^{\circ}$ lines or red $0^{\circ}$ and green $90^{\circ}$ ) provided only an estimate of the relative strength of $135^{\circ}$ vs. $45^{\circ}$ oriented line adaptation and of $0^{\circ}$ vs. $90^{\circ}$ line adaptation. Thus, assumptions that horizon- tal and vertical lines are equally effective and that each subject had two equal eyes with respect to eliciting the McCollough effects did not have to be made in the case of Condition 2.

\section{Results}

All subjects, regardless of condition, reported color differences between the halves of the combination test patterns that depended on grating orientation. In general, the reports were greenish tints contingent on $135^{\circ}$ and $90^{\circ}$ oriented lines and reddish tints contingent on $45^{\circ}$ and $0^{\circ}$ lines. Average ratings for test patterns based on observer data combined from Conditions 1 and 2 are presented in Figure 1. Clearly, subjects tended to rate the effects as equal for orthogonal halves of the combination test patterns; i.e., red tints were perceived as strong as green tints. This confirmed that the inspection patterns were roughly equated for brightness.

The subjects' magnitude estimates, however, decreased systematically as the similarity between the spatial frequencies of the inspection and test gratings decreased. Test patterns of spatial frequency greater or less than that of the inspection patterns elicited weaker or less saturated McCollough effects. Although the sample of spatial frequencies is insufficient to draw any definite conclusions, the drop-off rate seems to be sharper for test gratings of greater spatial frequency than for those of lesser spatial frequency.

Five subjects reported the interocular transfer of some but not all of their perceived color effects to the unadapted eye. In all such cases, the transferred effects were weaker than the corresponding elicited

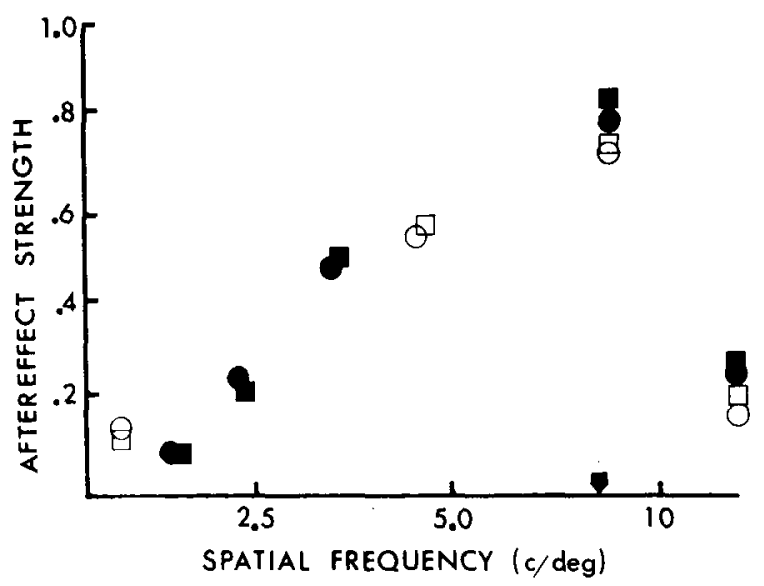

Figure 1. Average strength of aftereffects $(N=20)$ produced by viewing $0^{\circ}(\bullet), 45^{\circ}(O), 90^{\circ}(\square)$, and $135^{\circ}(\square)$ achromatic test gratings following adaptation to red or green colored inspection gratings of the same line orientation. Responses are depicted for six different spatial frequencies of test pattern. The strength of aftereffect elicited by any particular spatial frequency is defined in this and all subsequent diagrams as the ratio of its perceived saturation to the perceived saturation of the effect elicited by the inspection spatial frequency. Arrow indicates the spatial frequency of the reference (inspection) grating. 
effects. Three of the five subjects reporting transfer perceived the transferred color effects as being antagonistically organized. Thus, following monocular exposure to red $135^{\circ}$ lines, achromatic $135^{\circ}$ test gratings appeared green when viewed with these subjects' adapted eye, but reddish-pink when viewed with the unexposed eye. Other subjects (in Condition 1 only) reported color aftereffects in one eye contingent upon the line orientations that were inspected by the contralateral eye. For example, following inspection of red $90^{\circ} /$ green $0^{\circ}$ lines with the left eye and green $135^{\circ} /$ red $45^{\circ}$ lines with the right eye, two subjects saw McCollough effects with the left eye not only contingent upon $90^{\circ}$ and $0^{\circ}$ test gratings (the ipsilateral adaptation), but also contingent upon $135^{\circ}$ and $45^{\circ}$ test gratings (the contralateral adaptation).

Two $t$ tests of the difference between the rated strength of the McCollough effects for the four grating orientations (e.g., green $0^{\circ}$ vs. green $135^{\circ}$ aftereffects or red $90^{\circ}$ vs. red $45^{\circ}$ aftereffects) revealed no significant differences. The mean subject magnitude estimates as well as standard deviations for the four types of line-grating orientations are shown in Table 1. Results are given for test line gratings identical in spatial frequency to the inspection gratings. The similarity among the mean values for all orientations indicates that pairs of inspection gratings differing in their angular orientation but not in their angular separation produce McCollough effects of similar perceived magnitude.

\section{Discussion}

Fidell (1970) found that McCollough effects could be produced by all pairs of inspection gratings that were orthogonally separated in their line orientation. This experiment supports that finding. Equally strong McCollough effects were produced with both $45^{\circ} / 135^{\circ}$ and $0^{\circ} / 90^{\circ}$ inspection grating sequences. In fact, using the Condition 2 procedure, we found that four different orientation-contingent color aftereffects (of comparable strength) could be simultaneously induced monocularly even though only two types of color stimuli were paired with them.

Table 1

Comparison of McCollough Effect Strengths Following Inspection of Four Orientations of Line Gratings

\begin{tabular}{llllll}
\hline & & \multicolumn{4}{c}{ Test Pattern Orientation* } \\
\cline { 2 - 6 } $\begin{array}{c}\text { Perceived After- } \\
\text { effect Tint }\end{array}$ & $0^{\circ}$ & $45^{\circ}$ & $90^{\circ}$ & $135^{\circ}$ \\
\hline Red & $\overline{\mathrm{X}}$ & 3.82 & 3.45 & & \\
$(\mathrm{~N}=20)$ & $\sigma$ & 1.50 & 1.90 & & \\
Green & $\overline{\mathrm{X}}$ & & & 3.47 & 3.76 \\
$(\mathrm{~N}=20)$ & $\sigma$ & & & 1.81 & 1.71 \\
\hline
\end{tabular}

*In all cases the spatial frequency of the test gratings corresponds approximately to that of the inspection gratings $(8.3 \mathrm{c} / \mathrm{deg})$.
Condition 2 was run because it seemed that sequential, instead of simultaneous, induction of the effects in Condition 1 might allow the first set more time than the second set to decay in strength. Hence, the experimental design may have artifactually produced a difference in estimated magnitude aftereffect. This argument seems to be all the more cogent in view of reports that the McCollough effect decays as a linear (Riggs, White, \& Eimas, 1974) or a negative power function (MacKay \& MacKay, 1974) of time. However, three arguments can be advanced against this position. First, there were no significant differences between the results produced by the two inspection conditions: both the average values and the standard deviations of the two sets of data were similar. Second, the order of the two inspection sessions of Condition 1 was randomly counterbalanced. Third, contrary to decay function predictions, only 2 of the 10 subjects in Condition 1 rated their most recently acquired aftereffects as strongest, but 4 rated their first acquired as strongest. Evidently, the $10 \mathrm{~min}$ allowed to elapse between sessions in Condition 1 did not affect the perceived magnitude of the orientationcontingent color aftereffects. For these reasons, the two sets of data were combined for analysis. However, these similarities do not a posteriori rule out the possibility that binocular transfer of the afterphenomenon may have influenced the subjective response measures in Condition 1.

Why earlier acquired aftereffects should be of the same strength as later acquired ones is puzzling. Perhaps the strength of the McCollough effect follows a very complex decay function. In this context, Mayhew and Anstis (1972) found that the magnitude of the motion-contingent color aftereffect, an analogue of the McCollough effect, increased after a 20-min rest period. Since the interval between the test-retest of the first acquired aftereffect in Group 1 was about $15 \mathrm{~min}$, it may be that the first aftereffect increased in strength during this period. On the other hand, the McCollough effects remain persistently strong long after their initial elicitation. For instance, Jones and Holding (1975) found that when subjects are tested at intervals up to $2040 \mathrm{~h}$ after a 15 -min induction period, the McCollough effect remains at better than half strength. Extrapolations indicate that the effect could last 6 months or longer. In view of such extreme temporal characteristics, a 15-min test-retest delay seems hardly significant provided the effect's decay rate is linear.

\section{EXPERIMENT 2}

The first experiment demonstrated that the strength of the McCollough effect is not greatly affected by changing the angular orientation of the inspection gratings. Since manipulation of other spatial charac- 
teristics might produce similar results, we chose to extend our description of the effects by varying the contour completeness and contour sharpness of the inspection gratings. Interest in the first parameter was stimulated by a report that reducing the number of grating bars in the inspection pattern (when lowering the spatial frequency of the grating) does not decrease the strength of the McCollough effect (Stromeyer, 1972). It might be inferred from this example that maintaining the number of grating bars but altering their continuity would also produce no noticeable effect. The results provided by changing the second parameter potentially offerred to distinguish between two accounts of the McCollough effect (i.e., Harris \& Gibson, 1968; McCollough, 1965; see overall discussion). In particular, Harris and Gibson (1968) found that lowering the bar focus while maintaining the maximum intensity difference of the test gratings (i.e., blurring) does not weaken the strength of the McCollough effect. They developed an alternative explanation of the phenomenon to account for this data. However, they did not determine if lowering the bar focus of the inspection gratings had any effect. One might resolve the issue by adapting different groups of subjects to blurred or focused inspection bars. The relative magnitude of their aftereffect responses to both blurred and focused test bars could then be determined.

\section{Method}

Subjects. The subjects were 15 male and 15 female University of British Columbia students. Ten of the subjects had participated in the first experiment some 6 weeks earlier. The 20 other subjects were unacquainted with the McCollough effect. The mean age of all the subjects was approximately 22 years.

Apparatus and grating stimuli. The optical apparatus and grating stimuli were identical to those used in the first experiment except that a set of $0^{\circ}$ and $90^{\circ}$ interrupted-line grating patterns replaced the $45^{\circ}$ and $135^{\circ}$ line grating patterns. These two new series of patterns had approximately the same projected field dimensions and bar densities as the corresponding continuous-line grating patterns. But each black bar was divided into equal segments of black and white spaces (see Figure 2), subtending about $0.12^{\circ}$ of visual angle in length and $0.04^{\circ}$ of visual angle in width. Combination test patterns of the same visual dimensions were also constructed. They had the following spatial frequencies: 2.0, 3.4, $5.4,8.3$, and $11.6 \mathrm{c} / \mathrm{deg}$.

Procedure. The subjects were divided into two inspection groups. Those in Condition 1 were adapted monocularly to colored inspection gratings for two separate sessions lasting $10 \mathrm{~min}$ each. During one session, they viewed an alternating sequence of $0^{\circ}$ and $90^{\circ}$ oriented continuous-line gratings. In the other session, they viewed, with the previously unadapted eye, interrupted-line gratings composed of the same line orientations. This second session followed the first by approximately $12 \mathrm{~min}$ (representing the 10-min first session adaptation time plus the 2-min first session test time interval). Random assignment insured that some subjects saw the continuous-line grating patterns first, while others saw the interrupted-line grating patterns first. Magnitude estimates were gathered by procedures similar to those employed in Experiment 1.

The subjects in Condition 2 were also adapted to alternating $0^{\circ}$ and $90^{\circ}$ oriented line-grating patterns in two separate sessions. But, in both sessions, the same inspection patterns (i.e., contin-

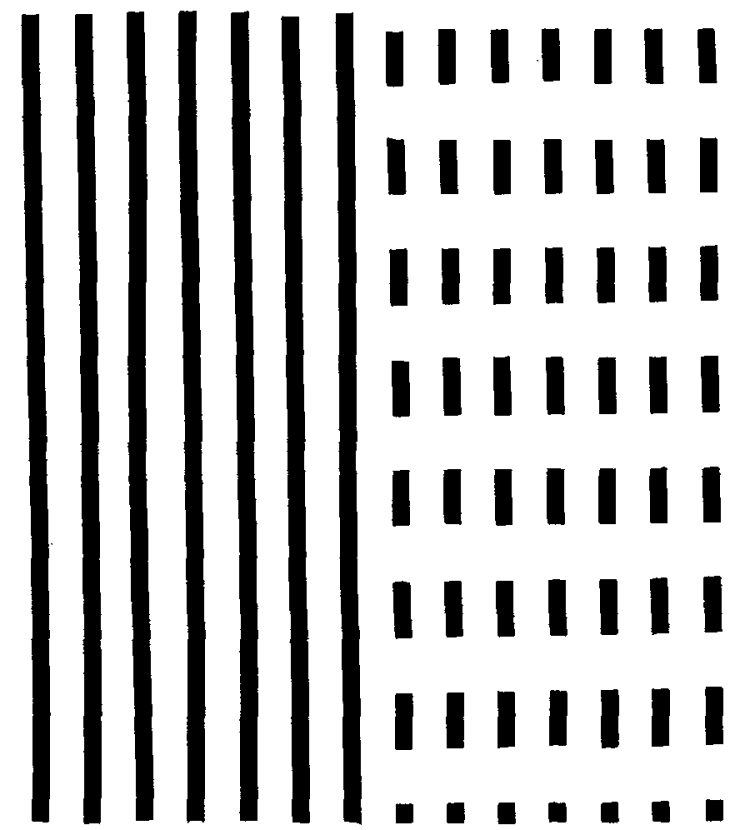

Figure 2. Portion of interrupted line grating inspection pattern compared with corresponding portion of continuous line pattern (drawn to scale).

uous line gratings) were used. In one session, the patterns were sharply focused so that the individual bars were clearly visible, while in the other, the patterns were deliberately defocused so that the individual bars were almost indistinguishable. The magnitude of "blur was measured as the number of diopters of spherical correction required to restore the image of the grating pattern to a sharp focus. This was found to be approximately -1 diopter.

Before testing began, the subjects were instructed in the experimental procedure, screened for color vision anomalies, and tested to determine if they perceived any tints contingent upon the grating orientation of the test patterns (none of the subjects, including those previously adapted in Experiment 1, reported such color effects).

\section{Results}

For both inspection conditions, the aftereffects reported were approximately complementary in hue to the adaptation colors. Generally, green tints were perceived as contingent on $90^{\circ}$ oriented bars (whether they were blurred, focused, or interrupted) and red tints were perceived as contingent on $0^{\circ}$ oriented lines. But focused continuous bar gratings elicited more overall subject responses than blurred or interrupted bar gratings. The average magnitude estimates of aftereffect strength are shown in Figures 3 and 4.

In Figure 3, average magnitude responses to continuous (solid symbols) and interrupted (open symbols) test gratings are shown for test patterns of two different line orientations $\left(0^{\circ}\right.$ and $\left.90^{\circ}\right)$ and five different spatial frequencies. Subjects inspected red horizontal and green vertical grating patterns which were composed of either continuous or interrupted lines. Thus, two complete sets of results are depicted: the responses of subjects $(N=15)$ to continuous and interrupted line test gratings following adapta- 


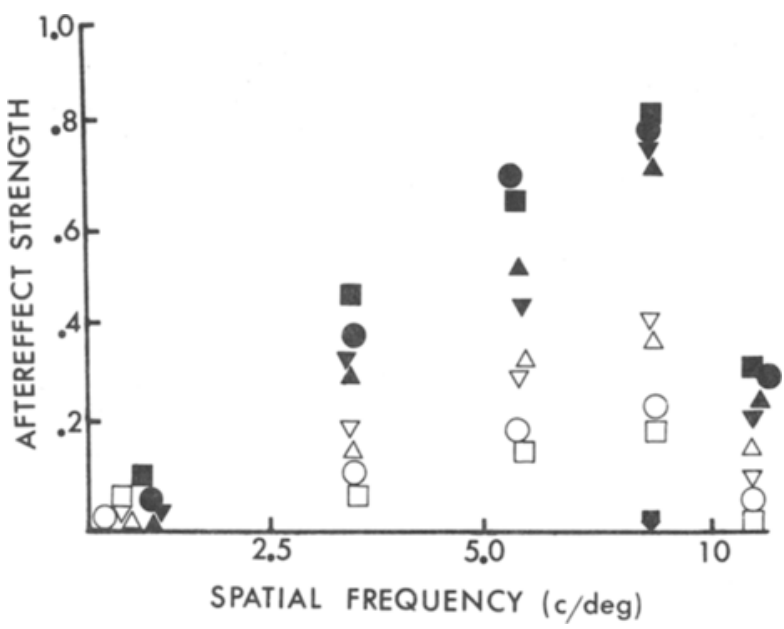

Figure 3. Average strength of aftereffects $(N=15)$ produced following inspection of red $0^{\circ}$ continuous $(\square)$, red $0^{\circ}$ interrupted $(\Delta)$, green $90^{\circ}$ continuous $(O)$ and green $90^{\circ}$ interrupted $(\nabla)$ colored lines. Responses to both continuous (solid symbols) and interrupted (open symbols) achromatic test gratings of the appropriate line orientation are depicted for five different spatial frequencies. Arrow indicates the spatial frequency of the reference gratings.

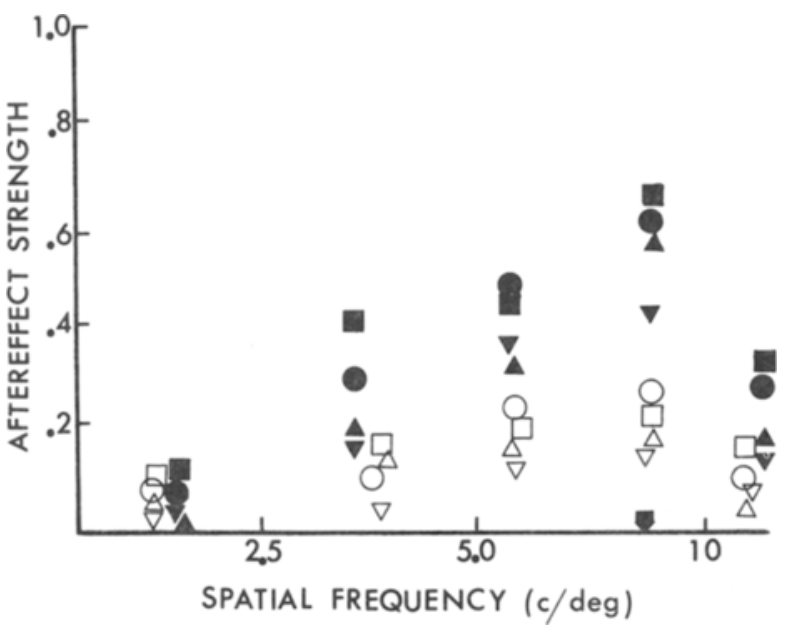

Figure 4. Average strength of aftereffects $(N=15)$ produced following inspection of red $0^{\circ}$ focused $(\square)$, red $0^{\circ}$ blurred $(\Delta)$, green $90^{\circ}$ focused $(O)$, and green $90^{\circ}$ blurred $(V)$ colored lines. Responses to both focused (solid symbols) and blurred (open symbols) achromatic test gratings of the appropriate line orientation are depicted for five different spatial frequencies. Arrow indicates the spatial frequency of the reference grating.

tion to continuous line inspection gratings and the responses of subjects $(N=15)$ to the same test gratings following adaptation to interrupted line inspection gratings.

Similarly, in Figure 4, average magnitude responses to focused (solid symbols) and blurred (open symbols) test gratings are shown. Again, two complete sets of results are depicted: the responses of subjects $(\mathrm{N}=$ $15)$ to focused and blurred line inspection gratings and the responses of subjects $(N=15)$ to the same test gratings following adaptation to blurred line inspection gratings.
In both figures, the estimate values clearly increase as a function of spatial frequency similarity between the inspection and test gratings. This relationship occurs for all inspection conditions regardless of the other spatial characteristics of the test patterns. Nevertheless, for the same test spatial frequency, continuous line gratings produce, on the average, stronger magnitude responses.

In Condition 1, responses to test gratings are determined in part by the type of inspection pattern. Subjects adapted to continuous line inspection gratings gave the strongest response to continuous line test gratings. Likewise, subjects adapted to interrupted line inspection gratings gave the strongest responses to interrupted line test gratings. The magnitude responses to the interrupted gratings, however, are considerably lower than those to the continuous gratings. In Condition 2, the results are less systematic. Even after adaptation to blurred inspection gratings, the subjects assigned smaller magnitude values to the blurred test gratings than to the focused. Overall, they gave fewer responses ( $48 \%$ compared to $31 \%$ ) when viewing with the eye adapted to blurred grating contours. Thus, responses were not specific to the inspection stimuli as they were in Condition 1 .

To measure the relative strength of aftereffects resulting from the viewing of the different inspection gratings, $t$ tests were used. In all cases, the differences in mean ratings following continuous and interrupted adaptations (Condition 1) or focused and blurred adaptations (Condition 2) were not significant. The close similarity among the observer mean values is indicated in Table 2 for four test gratings matching the inspection gratings in spatial frequency and orientation.

Nonparametric sign tests (Ferguson, 1971, pp. 324-325) were applied to the same data to deter-

Table 2

Comparison of Orientation Contingent-Color Aftereffect Strengths Following Inspection of Either Continuous (C) and Discontinuous (D) or Focused (F) and Blurred (B) Line Gratings

\begin{tabular}{|c|c|c|c|c|c|c|c|}
\hline \multirow[b]{3}{*}{ Line } & & \multicolumn{6}{|c|}{ Test Pattern* } \\
\hline & & \multicolumn{3}{|c|}{$0^{\circ}$} & \multicolumn{3}{|c|}{$90^{\circ}$} \\
\hline & & $\mathrm{FC}$ & FD & $\mathrm{BC}$ & $\mathrm{FC}$ & FD & $\mathrm{BC}$ \\
\hline & & \multicolumn{6}{|c|}{ Inspection Condition $1(\mathrm{~N}=15)$} \\
\hline $\mathrm{C}$ & $\begin{array}{l}\overline{\mathrm{X}} \\
\sigma\end{array}$ & $\begin{array}{l}3.39 \\
1.85\end{array}$ & $\begin{array}{l}1.30 \\
1.63\end{array}$ & & $\begin{array}{l}3.17 \\
1.41\end{array}$ & $\begin{array}{l}1.22 \\
1.40\end{array}$ & \\
\hline \multirow[t]{2}{*}{$\mathrm{D}$} & $\begin{array}{l}\overline{\mathrm{X}} \\
\sigma\end{array}$ & $\begin{array}{l}2.67 \\
2.10\end{array}$ & $\begin{array}{l}1.41 \\
1.19\end{array}$ & & $\begin{array}{l}3.00 \\
1.76\end{array}$ & $\begin{array}{l}1.39 \\
1.20\end{array}$ & \\
\hline & & \multicolumn{6}{|c|}{ Inspection Condition $2(\mathrm{~N}=15)$} \\
\hline $\mathrm{F}$ & $\begin{array}{l}\overline{\mathrm{X}} \\
\sigma\end{array}$ & $\begin{array}{l}3.00 \\
1.97\end{array}$ & & $\begin{array}{l}1.00 \\
1.46\end{array}$ & $\begin{array}{l}2.70 \\
1.81\end{array}$ & & $\begin{array}{r}.75 \\
1.44\end{array}$ \\
\hline B & $\begin{array}{l}\overline{\mathrm{X}} \\
\sigma\end{array}$ & $\begin{array}{l}2.60 \\
2.11\end{array}$ & & $\begin{array}{l}.63 \\
.98\end{array}$ & $\begin{array}{l}2.35 \\
1.81\end{array}$ & & $\begin{array}{r}.59 \\
1.81\end{array}$ \\
\hline
\end{tabular}

*In all cases the spatial frequency of the test gratings corresponds approximately to that of the inspection gratings $(8.3 \mathrm{c} / \mathrm{deg})$. 
mine whether the type of test pattern rather than the type of inspection pattern affected the magnitude estimates. In fact, the mean observer ratings for both the "interrupted" and "blurred"' test grating patterns were significantly different from those for the "continuous-focused" patterns. Subjects in Condition 1, when viewing with the eye adapted to interrupted lines, rated the aftereffects produced by the continuous line horizontal $(Z=2.04, p<.05)$ and vertical $(Z=2.27, p<.05)$ gratings as considerably stronger than the aftereffects produced by the corresponding interrupted line gratings. When viewing with the eye adapted to continuous inspection gratings, the same subjects also rated the aftereffects produced by the continuous line horizontal $(Z=2.26$, $\mathrm{p}<.05)$ and vertical $(Z=2.47, \mathrm{p}<.05)$ gratings as strongest. Likewise, the subjects in Condition 2 , whether viewing with the eye adapted to blurred or focused gratings, rated the aftereffect produced by the focused horizontal $(\mathrm{Z}=2.47, \mathrm{p}<.05 ; \mathrm{Z}=$ $2.31, \mathrm{p}<.05$, respectively) and vertical $(\mathrm{Z}=2.11$, $\mathrm{p}<.05 ; Z=2.27, \mathrm{p}<.05$, respectively) gratings as strongest.

\section{Discussion}

The results of the second experiment reveal that the strength of the McCollough effect, as measured by the average magnitude ratings given by the subjects, is not significantly reduced by either interrupting or blurring the inspection gratings. Thus, we cannot argue that continuous line gratings are any more effective than interrupted or blurred line gratings (of otherwise identical spatial characteristics) for building up McCollough effects. Test patterns of continuous line gratings, however, always yield the most vivid color aftereffects regardless of the type of adaptation. Insofar as contour-induced color aftereffects are not specific to the completeness or focus of the contour used for adaptation, they resemble curvature-induced (Riggs, 1973) and angle-induced color (White \& Riggs, 1974) and motion-contingent aftereffects (Stromeyer \& Mansfield, 1970). Both the curvature and angular effects are also not dependent upon the degree of curvature or angle used for adaptation; test patterns of stronger curvature or angle always yield the most vivid color aftereffects.

Obviously, these findings contradict the report of Harris and Gibson (1968) claiming that blurring bars (by an unspecified amount) in the test pattern has no measurable effect. On the contrary, in this study at least, blurring (by +1 diopter) tends to reduce perceived aftereffect strength much in the same way as lowering contrast intensity does (Ellis \& Castellan, Note 4; Harris \& Barkow, Note 5). The decrement may well be due to the elimination of clear-cut edges in the grating though, curiously, blurring the inspection grating bars did not produce a similar effect.

\section{GENERAL DISCUSSION}

The extremely robust color aftereffects reported in this paper are analogues of the effects first produced by McCollough in 1965 . Originally, these phenomena were attributed to the specific adaptation of monocularly driven edge detectors varying in their wavelength sensitivity. Supposedly, the firing rate of detectors tuned to the orientation and color of the inspection stimuli is suppressed for an extended period following inspection. Consequently achromatic lines of similar orientation presented as test stimuli during this period of reduced activity are more vigorously signaled via edge detectors sensitive to the same orientation but to different wavelengths: hence, the opposite color aftereffects.

Similar physiological descriptions have been proposed with slight modifications by others. For instance, Harris and Gibson (1968) suggest that the effect is mediated by the adaptation of sensory units (i.e., "dipoles") more rudimentary than those described by McCollough (1965). And Murch (1972) suggests that the effect is the result of the adaptation of opponent-process color receptors in the lateral geniculate nucleus feeding into orientation detectors in the cortex. Such explanations, however, do not gather much support from psychophysical (cf.Jameson, 1972; Skowbo, Gentry, Timney, \& Morant, 1974; Timney, Gentry, Skowbo, \& Morant, 1974) or electrophysiological investigations (Dow \& Gouras, 1973; Hubel \& Wiesel, 1968) of the higher primate visual system. In fact, the sensory units and connections required by these adaptation models are not conspicuously present in the cortices of rats, cats, monkeys, or men. Those found simply do not display the appropriate response characteristics (cf. Jones \& Holding, 1975; MacKay \& MacKay, 1974; Riggs, White, \& Eimas, 1974). Apparently for this reason, other investigators have argued that the effect is probably mediated by perceptual learning or neural plasticity in the central processes. On the one hand, Leppmann (1973) and Skowbo et al. (1974) proposed that a learned association is formed between the orientational and negative color aspects of the inspection stimuli in a process similar to classical conditioning in which the firing of orientation detectors acts as a conditioned stimulus which has become associated with the adaptation of color receptors (the unconditioned stimulus). On the other hand, Creutzfeldt (1973) has argued that the aftereffects may be due to increased inhibitory synaptic linkage between the "excited neurons." In this regard, Creutzfeldt and Heggelund (1975) found that exposure of adult cats to vertical stripes might modify (temporarily) the functional organization of the visual cortex.

Despite efforts to fit the framework of facts known 
about the McCollough effect, all the above theories fall short in that purpose. Some of the apparent shortcomings may be briefly summarized in terms of our findings. First of all, models based on orientation detectors, either color coded or coupled to color coders, would not seem to predict that color aftereffects contingent on right and left $45^{\circ}$ line gratings would be as strong as those contingent on horizontal and vertical gratings. It is well known that a variety of visual effects exhibit a meridional effect (Appelle, 1972). Acuity, detection, and other visual functions seem to be better when the targets are oriented at vertical and horizontal, and poorest at orientations between (obliques). If the visual system possesses separate sets of analyzers for different orientations, and if these are responsible for both the McCollough effect and the oblique effect, the effect should be stronger when it is made contingent on vertical or horizontal lines than when it is made contingent on obliques. This was not the case.

Second, the dipole model would not be consistent with our findings in the second experiment, which incidentally contradict the original observations upon which the model is based. Harris and Gibson (1968) offered the dipole as a hypothetical sensory unit to explain why blurring test bars without changing their black-white intensity difference did not weaken the color aftereffect, their argument being that defocusing would tend to reduce the firing rate of contour detectors but not that of dipoles, which have no spatial stimulus preferences. However, we found the opposite: blurring the test gratings by approximately +1 diopter reduced subjective estimates of aftereffect strength, but blurring the inspection gratings by the same amount did not.

Third, models based on perceptual learning or cortical plasticity hypotheses are at some pains to explain why the strongest color effects are not elicited by the test gratings having the same stimulus attributes as the inspection gratings. In Experiment 2, it was found that after inspection of either interrupted or blurred patterns, the most vivid aftereffects are seen with complete or focused test contours. Adaptation, therefore, seems to be specific to both the orientation and spatial frequency of the inspection gratings, but not to the other spatial parameters. Doubtless, learned color associations with interrupted lines could readily generalize to complete lines. The laws of classical conditioning would, indeed, predict such a phenomenon. But these laws would concomitantly predict that a response decrement and not a response increment in aftereffect strength should occur when the stimuli characteristics of the test pattern deviate (within reasonable limits) from those of the inspection stimuli.

Finally, all these explanations are tenuously linked to neurophysiological evidence. For example, in one case, two different models claim to be corroborated by the same electrophysiological findings. Breitmeyer and Cooper (1972) support one theory by arguing that Hubel and Wiesel (1968) "have demonstrated the existence of neurons in monkey striate cortex which respond optimally to lines of a particular orientation and color." Interestingly, Murch (1972) supports another by arguing that the same research reveals that "color-sensitive elements and edge detectors may be located in two distinct anatomical areas of the visual system." This example illustrates two inherent problems. First, present descriptions of visual physiology and visual function are sufficiently obscure to allow different and contradictory interpretations. Second, explanations of psychophysical phenomena frequently involve oversimplified views of the nervous system. For the present, as Skowbo et al. (1975) have pointed out, what is needed is more information as to the characteristics of the aftereffects, not weak and speculative neurophysiological model building.

\section{REFERENCE NOTES}

1. White, K. D., \& Ellis, S. R. McCollough effect: Pattern alternation rate influences establishment. Paper presented at the annual meeting of the Optical Society of America, Boston, October 1975.

2. White, K. D., \& Riggs, L. A. Luminance as a parameter in establishment and feeling of the McCollough effect. Paper presented at the 15th annual meeting of the Psychonomic Society, Boston, November 1974.

3. May, J. G., \& Matteson, H. H. Spatial frequency contingent color aftereffects. Paper presented at the annual meeting of the Psychonomic Society, Denver, November 1975.

4. Ellis, S. R., \& Castellan, K. The orientation-specificity of the McCollough effect: An equivalent contrast transformation. Paper presented at the annual meeting of the Association for Research and Vision and Ophthalmology, 1975.

5. Harris, C. S., \& Barkow, B. Colour/white grids produce weaker orientation specific aftereffects than do colour/black grids. Paper presented at the annual meeting of the Psychonomic Society, St. Louis, November 1969.

\section{REFERENCES}

Appelle, S. Perception and discrimination as a function of stimulus orientation: The "oblique effect" in man and animals. Pyychological Bulletin, 1972, 78, 266-278.

Breitmeyer, B. G., \& CoOper, L. A. Frequency-specific adaptation in the human visual system. Perception \& Psycho. physics, 1972, 11, 95-96.

Creutzfeldt, O. D. Some neurophysiological considerations concerning memory. In H. P. Zippel (Ed.), Memory and transfer of information. New York: Plenum Press, 1973. Pp. 293-302.

Creutzfeldt, O. D., \& Heggelund, P. Neural plasticity in visual cortex of adult cats after exposure to visual patterns. Science, 1975, 188, 1025-1027.

Dow, B. M., \& Gouras, P. Color and spatial specificity of single units in rhesus monkey foveal striate cortex. Journal of Neurophysiology, 1973, 36, 79-100.

Favreau, O. E., Emerson, V. F., \& Corballis, M. C. Motion perception: A colour-contingent aftereffect. Science, 1972, 176, 78-79.

Ferguson, G. A. Statistical analysis in psychology and education (3rd ed.). New York: McGraw-Hill, 1971. 
FIDELL, L. S. Orientation specificity in chromatic adaptation of human "edge-detectors." Perception \& Psychophysics, 1970, 8. 235-237.

HARRIs, C. S., \& Gibson, A. R. Is orientation-specific colour adaptation in human vision due to edge detectors, afterimages, or "dipoles"? Science, 1968, 162, 1506-1507.

HePler, N. Color: A motion-contingent aftereffect. Science, 1968, 162, 376-377.

Hubel, D. H., \& WiEsel, T. N. Receptive fields and functional architecture of monkey striate cortex. Journal of Physiology (London), 1968, 195, 215-243.

JAmEson, D. Theoretical issues of color vision. In D. Jameson \& L. Hurvich (Eds.), Handbook of sensory physiology: Visual psychophysics (Vol. VII/4). Berlin: Springer-Veriag, 1972. Pp. 381-412.

Jones, P. D., \& Holding, D. H. Extremely long-term persistence of the McCollough effect. Journal of Experimental Psychology: Human Perception and Performance, 1975, 1, 323-327.

Leppmann, P. K. Spatial-frequency dependent chromatic aftereffects. Nature, 1973, 242, 411-412.

LOVEgrove, W. J., \& Over, R. Color adaptation of spatial frequency detectors in the human visual system. Science, $1972,176,541-543$.

Lovegrove, W. J., Over, R., \& Broerse, J. Colour selectivity in motion after-effect. Nature, 1972, 238, 334-335.

MACKAY, D. M., \& MACKAY, V. Orientation-sensitive aftereffects of dichoptically presented colour and form. Nature, 1973, 242, 477.479.

MacKay, D. M., \& MacKay, V. The time course of the McCollough effect and its physiological implications. Journal of Physiology (London), 1974, 237, 38P-39P.

MaYhew, J. E. W., \& Anstis, S. M. Movement aftereffects contingent on color, intensity, and pattern. Perception \& Psychophysics, 1972, 12, 77-84.

McCollough, C. Color adaptation of edge-detectors in the human visual system. Science, 1965, 149, 1115-1116.

Mikaelian, H. H. Color selectivity and interocular transfer of color specific tilt aftereffects. Vision Research, 1975, 15, 157.

Murch, G. M. Binocular relationships in a size and color orientation specific aftereffect. Journal of Experimental Psychology, 1972, 93, 30-34.

Riggs, L. A. Curvature as a feature of pattern vision. Science, 1973, 181, 1070-1072.

Riggs, L. A., White, K. D., \& Eimas, P. D. Establishment and decay of orientation-contingent aftereffects of color. Perception \& Psychophysics, 1974, 16, 535-542.

Skowbo, D., Gentry, T., Timney, B., \& Morant, R. B. The McCollough effect: Influence of several kinds of visual stimulation on decay rate. Perception \& Psychophysics, 1974, 16. 47-49.

Skowbo, D., Timney, B. N., Gentry, T. A., \& Morant, R. B. McCollough effects: Experimental findings and theoretical accounts. Psychological Bulletin, 1975, 82, 497-510.

StromeYer, C. F. Further studies of the McCollough effect. Perception \& Psychophysics, 1969, 6, 105-110.

STROMEYER, C. F. Edge-contingent color aftereffects: Spatial frequency specificity. Vision Research, 1972, 12, 717-732.

Strome Yer, C. F., \& Mansfield, R. J. W. Colored aftereffects produced with moving edges. Perception \& Psychophysics, 1970, 7, 108-114.

TefT, L. W., \& Clark, F. T. The effects of stimulus density on orientation specific aftereffects of color adaptation. Psychonomic Science, 1968, 11, 265-266.

Timney, B. N., Gentry, T. A., Skowbo, D., \& Morant, R. B. Chromatic grating thresholds and the McCollough effect. Vision Research, 1974, 14, 1033-1035.

WALKER, J. T. A texture-contingent visual motion aftereffect. Psychonomic Science, 1972, 28, 333-335.

WhITE, K. D., \& RigGS, L. A. Angle-contingent color aftereffects. Vision Research, 1974, 14, 1147-1154.

(Received for publication March 1977; revision accepted November $9,1977$. 